\title{
Qualificação, Competência Técnica e Inovação no Ofício Docente para a Melhoria da Qualidade do Ensino Fundamental(1)
}

\author{
Laura da Veiga \\ Maria Ruth Siffert Diniz Teixeira Leite \\ Vanda Catarina Duarte
}

\begin{abstract}
Resumo
O objetivo desse artigo é discutir a capacitação docente em relação ao desempenho escolar do aluno e ao contexto da diversidade socioeconômica instaurada nas escolas a partir da década de 90 . O problema de pesquisa foi o seguinte: qual a importância da capacitação no desempenho dos docentes para melhorar o rendimento escolar dos alunos dos municípios de Januária e Montes Claros? Os dados foram coletados, nesses municípios, entre outubro de 1999 e fevereiro de 2000 e se referem à situação socioeconômica das famílias das crianças matriculadas nas escolas da amostra, ao perfil do professorado e ao apoio pedagógico disponível nas escolas. A amostra foi composta por seis escolas em cada município (três da rede estadual e três da rede municipal), totalizando 12 escolas. A análise da capacitação está baseada no tipo de treinamento oferecido aos professores da rede pública por meio de programas implementados nos estados de Minas Gerais e São Paulo no período 1996-1998. A principal conclusão é que a capacitação na forma como tem sido oferecida não tem contribuído efetivamente para desenvolver as competências demandadas dos docentes para apoiar crianças oriundas de ambientes familiares desfavoráveis aos desafios da escolarização.
\end{abstract}

Palavras-chave: capacitação; diversidade; desempenho escolar; professor.

\begin{abstract}
This article discusses the importance of teachers training to the pupils performance in a socioeconomic context established at schools from the 1990s on. The research problem was the following: what was the importance of the teachers training in the pupils performance from Januaria and Montes Claros? The data were collected in Januária and Montes Claros from October 1999 to February 2000. They were referred to the pupils families socioeconomic background, to the teachers profile and the pedagogical support available at the schools. The sample was made up of six schools in each municipality, being three from Minas Gerais, Brazil, and three from the municipality system; amounting to 12 schools. Indexes were established in order to compare the data collect from the teachers, schools heads and members of the pupils families. The main conclusion was that the kind of teachers' training offered did not succeed in improving school performance for childrens belonging to families from low socioeconomic background.
\end{abstract}

Key words: capacity; diversity; school performance; teacher. 


\section{INTRODUÇÃO}

A capacitação de professores tem sido apontada como um dos fatores favoráveis à melhoria da qualidade do ensino no Brasil. Estudos sobre o assunto ressaltam a sua importância, considerando-a como variável que tem impacto diferencial no rendimento da aprendizagem dos alunos, embora reconheçam a dificuldade de serem oferecidos cursos eficazes e que atinjam a grande maioria dos profissionais da área. A extensão territorial e as diferenças regionais do país permitem colocar em dúvida se cursos pontuais, padronizados e definidos por um sistema central, refletem, de fato, as necessidades dos professores que, a partir dos anos 90, passaram a desempenhar um novo papel no cenário educacional brasileiro. A legislação vigente sobre o setor propiciou a implantação de um modelo de ensino mais flexível e que contempla a aceitação da diversidade socioeconômica e cultural do alunado nas escolas regulares do ensino fundamental. O que se pretende neste artigo é discutir a capacitação docente em relação ao desempenho escolar do aluno e ao contexto da diversidade socioeconômica instaurada nas escolas a partir da década de 90. Postula-se que uma capacitação docente adequada poderia ser um instrumento eficaz para auxiliar as escolas na difícil tarefa de atender, satisfatoriamente, aqueles alunos provenientes de ambientes desfavoráveis à escolarização.

Os dados aqui utilizados foram coletados nos municípios de Montes Claros e Januária entre outubro de 1999 e fevereiro de 2000 e dizem respeito à situação socioeconômica das famílias das crianças matriculadas nas escolas escolhidas como amostra, ao perfil do professorado e ao apoio pedagógico disponível nas escolas. A amostra contemplou seis escolas em cada município (três da rede estadual e três da rede municipal), totalizando 12 escolas. A opção de selecionar escolas das duas redes de ensino foi para verificar se elas se diferenciam quanto à adoção de programas pedagógicos para lidar com as dificuldades de aprendizagem das crianças por elas atendidas. Os municípios de Montes Claros e Januária foram escolhidos por estarem situados em uma das regiões menos desenvolvidas de Minas Gerais e por apresentarem características socioeconômicas, culturais e educacionais diferenciadas, favorecendo as comparações entre ambos. Para fins da comparação entre os municípios, foram construídos índices a partir de dados obtidos em questionários aplicados aos professores (36), diretores (12) e às famílias das crianças das escolas (234). A análise da capacitação está baseada no tipo de treinamento oferecido aos professores da rede pública por meio de programas financiados pelo Banco Mundial, implementados nos estados de Minas Gerais e São Paulo entre 1996- 
$1998^{(2)}$. O problema que se quer investigar é se a capacitação, nos moldes em que vem sendo desenvolvida pelas secretarias estaduais de educação, amplia as capacidades dos docentes de modo a torná-los mais eficazes para enfrentar os desafios presentes no contexto escolar, em especial o representado pela incorporação de crianças oriundas de ambientes familiares marcados pela pobreza e exclusão.

\section{O Contexto da Diversidade}

A década de 80 veio confirmar a tendência de crescimento do acesso das crianças de 7 a 14 anos ao sistema de ensino formal. A aprovação da Emenda Constitucional 24/1983 (de autoria do Senador João Calmon) e a Carta Constitucional de 1988 se tornaram marcos legais para o início do processo de flexibilização do modelo educacional no Brasil e da inclusão da diversidade e da pluralidade pedagógica nas escolas públicas de ensino fundamental. A Lei de Diretrizes e Bases da Educação Nacional - LDB (Lei nº 9394), promulgada em 1996, alterou substancialmente as diretrizes educacionais no país, introduzindo, além de nova estrutura curricular e novos procedimentos pedagógicos e de gestão escolar colegiada, valores básicos de interesse da sociedade, direitos e obrigações dos cidadãos e respeito pela ordem democrática e pelas características de vida em cada região.

Conquanto se possa estar otimista com a expansão da cobertura propiciada pelo sistema escolar ${ }^{(3)}$, Nunes (1996, p. 476) aponta a necessidade de se atentar para a qualidade das vagas disponibilizadas, uma vez que “(...) persistem desequilíbrios na localização das escolas (oferta insuficiente onde há maior demanda, e vice-versa), um número excessivo de turnos que resulta em períodos exíguos de estudo em sala de aula, além da proliferação de classes multisseriadas”. Muitas escolas funcionam em mais de três turnos, o que encurta o período escolar para apenas duas ou três horas diárias. Agregam-se a isso problemas como estes: aumento do número de alunos nas salas de aula, paralisações por greves, faltas do professor e do aluno, rotatividade do professor, perda de tempo com atividades burocráticas e atraso no início das aulas.

A situação de ampliação do acesso escolar remete a outro problema, que é a diversidade da clientela. De acordo com Veiga (2001, p. 19) “(...) a ampliação da cobertura para a população de 7 a 14 anos havia incorporado cada vez mais crianças residentes nas áreas rurais e localidades pobres do interior do país e/ou oriundas de famílias situadas na base da pirâmide social que não detinham os recursos materiais e simbólicos para atuar complementarmente à escola para 
apoiar seus membros no processo de escolarização”. As escolas têm-se mostrado, de acordo com Gusso (1993, p. 159), incapazes de lidar com a diversidade das clientelas, principalmente a constituída pelas crianças mais pobres, marcadas por diferenças socioeconômicas e culturais que poderiam vir a sofrer dificuldades de adaptação aos ambientes escolares ${ }^{(4)}$.

Ao acesso praticamente universalizado, contrapõe-se também o baixo desempenho revelado pelo sistema. De acordo com dados do MEC/INEP (2000), a taxa de repetência no ensino fundamental brasileiro( ${ }^{(5)}$ passou de $30,3 \%$ em 1995/96 para 21,6\% em 1999/2000 e a taxa de evasão passou de 5,3\% para 4,8\% no mesmo período. Embora tenham melhorado, os índices de repetência e de evasão no país continuam altos se comparados com os dos demais países da América Latina, como a Argentina, que em 1997 tinha uma taxa de repetência de 5,7\%, e o Paraguai, de 8,4\% (PARAGUASSU, 2001, p. 3). Os resultados das avaliações do Sistema da Avaliação da Educação Básica (SAEB) do ano de 2001 mostram, por sua vez, que embora 97\% das crianças brasileiras estejam matriculadas na escola, o desempenho dos alunos é ainda baixo: na $4^{\mathrm{a}}$ série, por exemplo, os estudantes deveriam alcançar 175 pontos em Português, numa escala de pro-eficiência que chega a 350, mas a média verificada foi de 165,1. A média em Matemática foi de 176,3, quando deveria obter 250 na escala que alcança 425 pontos $^{(6)}$.

O desempenho continua bastante desigual: as escolas rurais mineiras registram um desempenho, em Português, na $4^{\mathrm{a}}$ série, similar ao das escolas de Sergipe e do Maranhão, ou seja, 149 pontos. Nas capitais, as crianças da $4^{\mathrm{a}}$ série alcançaram 191,5, obtendo assim 40 pontos de dianteira sobre os colegas do interior.

Uma complexa rede de fatores contribui para esse fraco desempenho do sistema. Segundo Bonamino e Franco (1998 apud BONAMINO, 2000, p. 47) podem ser destacados como explicação para o baixo rendimento das crianças e as elevadas taxas de repetência, fatores intra e extra escolares. Os primeiros dizem respeito aos baixos salários dos profissionais da educação, a influência política na designação dos professores e a infra-estrutura curricular insuficiente. Os extraescolares referem-se às condições de vida dos alunos e de suas famílias, acompanhamento da vida escolar da criança pelos pais e outros.

A literatura aponta para quatro conjuntos de fatores que podem interferir no processo de aprendizagem da criança. O primeiro tem que ver com as características das unidades escolares: qualificação e competência técnica dos profissionais, disponibilidade de infra-estrutura física e de material didático para as atividades escolares, adaptação dos currículos aos diferentes contextos 
socioculturais da clientela. O segundo conjunto leva em consideração as características de quem recebe a escolarização. O terceiro decorre do tipo de relações estabelecidas entre família e escola (VEIGA; BARBOSA, 1997, p. 4243) e o quarto refere-se ao perfil do professor. Adquirem importância particular todas as ações desenvolvidas pelas unidades escolares e sistema educacional para gerar condições mais adequadas para que as escolas e profissionais do ensino possam responder às necessidades de seus alunos. Quanto mais heterogêneo for o corpo discente, ou quanto maior for o número de crianças oriundas de famílias socialmente marginalizadas, maior será a competência exigida da escola para fornecer a atenção demandada para cada grupo de alunos. $\mathrm{Na}$ medida em que se amplia a cobertura, maior será o número de alunos oriundos de famílias que não detêm, no ambiente familiar, as condições que a literatura especializada tem apontado como facilitadoras da escolarização, o que aumenta, portanto, a responsabilidade da escola.

Dados de várias pesquisas mostram que crianças provenientes de ambientes socioeconômicos e culturais desfavoráveis são as que, em geral, apresentam maior dificuldade de aprendizagem. Em face dessa situação seria desejável e necessário que essas crianças tivessem sendo atendidas por professores mais bem capacitados e por escolas fortemente direcionadas para fornecer o apoio pedagógico, para que professores e alunos pudessem desenvolver suas atividades. Contudo o dados da pesquisa realizada em Januária e Montes Claros (Tabela 1) indicam a baixa associação entre o perfil do professorado e as condições socioeconômicas das famílias do alunado: 48\% das crianças provenientes de ambientes familiares desfavoráveis (situação socioeconômica baixa) são atendidas em escolas consideradas ruins com relação ao perfil dos professores que nelas atuam e 35,1\% estão em escolas classificadas como boas. Por sua vez, tem-se 54,4\% de alunos de melhor situação socioeconômica em instituições avaliadas como ruins e 34,2\% em escolas consideradas boas.

\section{Tabela 1: Situação Socioeconômica das Famílias e Perfil dos Professores das Escolas ${ }^{(7)}$}

\begin{tabular}{l|crr|r}
\hline \multirow{2}{*}{ SITUAÇÃO } & \multicolumn{2}{c|}{ PERFIL DOS PROFESSORES DAS ESCOLAS ${ }^{(8)}$} & \multirow{2}{*}{ TOTAL } \\
\cline { 2 - 4 } SOCIOECONÔMICA & Ruim & \multicolumn{1}{|c}{ Médio } & \multicolumn{1}{c}{ Bom } & \\
\hline Baixa & $37(48,0)$ & $13(17,0)$ & $27(35,1)$ & $77(100,0)$ \\
Média & $20(25,6)$ & $22(28,2)$ & $36(46,2)$ & $78(100,0)$ \\
Boa & $43(54,4)$ & $9(11,4)$ & $27(34,2)$ & $79(100,0)$ \\
TOTAL & $100(42,7)$ & $44(18,8)$ & $90(38,5)$ & $234(100,0)$ \\
\hline
\end{tabular}

Fonte: dados da pesquisa Descentralização, eficiência e equidade no ensino fundamental, Escola de Governo/Fundação João Pinheiro; FAPEMIG, 1999.

O desejável é que todas as escolas só recorressem a professores com perfil adequado. Mas como essa não é a situação observada nas escolas brasileiras, a 
segunda melhor alternativa seria designar professores mais experientes e mais bem qualificados para escolas que concentrem clientelas oriundas de ambientes menos favoráveis à escolarização. No entanto a tendência observada em várias pesquisas é que municípios mais desenvolvidos, em geral, têm um corpo de professores mais experiente e mais qualificado e, dentro dos municípios, as escolas que atendem à clientela das periferias são as que recorrem a professores menos qualificados e pouco experientes.

\section{Os Professores e a Capacitação para a Diversidade}

No panorama das pesquisas educacionais nas últimas décadas, as características do corpo docente são citadas como um dos fatores diretamente relacionados ao desempenho escolar. Estudiosos sobre o setor educacional têm dedicado especial atenção ao atual papel reservado ao professor e o valor atribuído a eles para que ocorra a adequada incorporação da diversidade cultural dos alunos e a pluralidade pedagógica nas escolas públicas de ensino fundamental. O que se postula é que padrões satisfatórios de interação e as dificuldades para lidar com o alunado social e culturalmente diferenciado estão fortemente ligados ao preparo insuficiente do corpo docente, o que poderia ser modificado por meio de programas contínuos de treinamento e capacitação desses docentes. Além disso, recomenda-se a elevação do nível de escolaridade mínima exigida dos profissionais que atuam nas escolas de ensino fundamental e de projetos de atenção pedagógica especial para alunos que revelem dificuldades de aprendizagem.

Com a promulgação da LDB/96, o modelo educacional brasileiro passa a se pautar por quatro grandes conjuntos de propostas a saber: a reorganização da escola (introdução do sistema de ciclos e/ou enturmação por faixa de idade, classes de aceleração, revisão dos procedimentos de avaliação escolar), revisão dos conteúdos ensinados nas escolas, introdução de avaliação externa para aferir o desempenho escolar e investimento na formação e melhoria das condições de trabalho dos professores.

Garrido e Carvalho (1999) afirmam que o papel reservado ao professor, após a reformulação do sistema educacional no país, deveria ser o de "refletir sobre a própria prática, problematizando-a, distinguindo as suas dificuldades, sugerindo hipóteses de solução, testando-as, procurando as razões subjacentes às suas ações, observando a reação dos alunos, verificando como aprendem.” Sendo assim, a produção do conhecimento seria deslocada para a sala de aula, onde os valores individuais do aluno e as características culturais do seu meio de origem seriam incorporados. Para tanto, a renovação exigiria uma mudança significativa 
do nível de formação e de identidade profissional dos professores, para que estivessem mais bem preparados para exercerem sua autonomia em sala de aula e maior controle sobre suas condições de trabalho. Ao professor caberia explorar a potencialidade dos seus alunos e tentar minimizar as diferenças cognitivas existentes, utilizando-se não só de novas técnicas pedagógicas adquiridas em treinamentos e programas de capacitação, como também da sua própria criatividade.

Perrenoud (1999) afirma que no novo modelo de ensino, mais flexível e dinâmico, “a construção de práticas e dispositivos alternativos requerem intenso trabalho de cooperação e inovação, de ruptura com o individualismo e a rotina”. Por isto, o perfil do professor constitui variável importante a ser considerada nas propostas pedagógicas formuladas para o sistema de ensino brasileiro.

Tais características fazem com que, no campo da capacitação docente, os desafios sejam grandes. Diferentes autores ${ }^{(9)}$ insistem em que as propostas de capacitação de docentes em curso têm apresentado baixa eficácia e apontam diferentes razões para isso. Dentre elas destacam-se a descontinuidade das ações; a desarticulação entre teoria e prática e entre estas e os sentimentos e valores dos professores; a ênfase excessiva nos aspectos normativos; a desvinculação com projetos coletivos e/ou institucionais; e a dissociação entre a formação e as outras dimensões do ofício do docente, como salários, condições trabalhistas e aspectos organizacionais.

As dificuldades que envolvem a capacitação têm sido ampliadas em face da complexidade que passou a envolver a escola nas duas últimas décadas: novos parâmetros curriculares, processos pedagógicos que buscam mais eficácia, sistema de ciclos escolares, maior autonomia da escola, universalização do acesso e inclusão. Enfrentar esses desafios requer uma capacitação continuada e voltada para a reflexão sobre a prática pedagógica do professor. A persistência de carências nas escolas e as inadequações dos modelos de capacitação têm resultado, de acordo com Mello (1991, p. 17), em professores despreparados para trabalhar com o tipo de aluno que predomina na escola pública, sentindo-se abandonados e sem assistência para enfrentar a difícil tarefa, para a qual não teriam recebido formação adequada. Aliás, essa tarefa torna-se mais complexa quanto maior for a diversidade cultural, social, cognitiva e econômica da clientela escolar (FORQUIN, 1995, p. 46) ${ }^{(10)}$. Veiga e Barbosa (1997, p. 47), similarmente, apontam o despreparo do corpo docente para lidar com diferenças e limitações do alunado, o que levaria à relativa incompetência institucional da escola para responder de forma apropriada ao desafio de incorporar as diferenças de códigos culturais e do manejo das habilidades cognitivas básicas. Os diferentes ritmos de aprendizagem e as formas de incorporar as necessidades de grupos específicos 
de alunos deveriam, assim, ser a tônica das capacitações oferecidas aos professores.

Para efeito da análise aqui desenvolvida, capacitação significa uma formação contínua que se dá após a formação inicial, tendo em vista a adequação dos conhecimentos existentes às exigências da atividade profissional, por meio do aperfeiçoamento do saber e das técnicas e atitudes necessárias ao exercício da profissão, de forma a assegurar a eficácia na formação dos alunos. Trata-se de uma definição baseada nas contribuições de autores como Marin (1995), Candau (1997), Nascimento (2000) e Santos (1998).

A análise das avaliações dos programas de capacitação de toda a rede pública realizada nos estados de Minas Gerais e São Paulo no período 1996-1998 revelou que, de modo geral, as capacitações não favoreceram as mudanças na atuação dos professores em sala de aula nem a participação em projetos temáticos ou interdisciplinares que indicassem um processo de atualização e questionamento de sua prática, salvo iniciativas pontuais. Da mesma forma não se percebeu indícios de ações pedagógicas inovadoras nas escolas e dos professores nem posturas educacionais comprometidas, como conseqüência de ações de capacitação. Além disso, parte considerável dos professores parece não ter incorporado as novas concepções conceituais relativas à educação e ao ensino. $\mathrm{O}$ trabalho pedagógico com crianças que apresentam dificuldades escolares e sociais não avançou satisfatoriamente e os projetos de trabalho dos docentes mantêm ainda uma concepção tradicional de ensino (DUARTE, 2002, p. 192194).

No estudo realizado por Duarte (2002) sobre o programa de capacitação realizado no estado de São Paulo foi identificado que parte das dificuldades resultaram da não observância de um conjunto de condições que viabilizassem a participação dos professores: os problemas envolveram questões operacionais elementares (equipamentos e espaço físico); aspectos relacionados à vida profissional do docente (compatibilização de horários e de calendário escolar, dupla jornada, ausência de ajuda de custo); e a própria concepção dos treinamentos (cursos pontuais, padronização dos conteúdos, não inclusão dos professores no processo). Portanto a programação das capacitações desconsiderou as próprias condições para os professores participarem da capacitação (horário e gastos adicionais) e, principalmente, a avaliação dos próprios docentes sobre as dificuldades que estariam enfrentando no cotidiano escolar. Em Minas Gerais, equívocos semelhantes foram observados, sendo que a definição dos conteúdos foi ainda mais centralizada do que a de São Paulo ${ }^{(11)}$. As capacitações mais bem sucedidas foram aquelas resultantes de processos cuidadosos de negociação entre as instituições capacitadoras, as delegacias de ensino e as escolas e as que 
envolverem, de forma ativa, os atores relevantes ao processo: diretores, autoridades educacionais e agências capacitadoras (DUARTE, 2002, p. 199).

Tais observações permitem delinear alguns dos requisitos para tornar uma capacitação eficaz. Candau (1997, p. 55) considera que a formação continuada de professores deve estruturar-se em torno de três eixos: a escola como locus privilegiado de formação, a valorização do saber docente e o ciclo de vida dos professores. O primeiro sugere que a formação deve partir das necessidades reais dos professores, dos problemas do seu dia-a-dia, e favorecer processos de pesquisa-ação e cooperação. O segundo contempla o princípio de que, mais do que valorizar os saberes das disciplinas, é preciso valorizar os saberes da experiência, considerados núcleo vital do saber do docente, a partir do qual o professor dialoga com as disciplinas e os saberes curriculares. Os saberes da experiência se fundamentam no trabalho cotidiano e no conhecimento de seu meio. O terceiro eixo refere-se às diferentes etapas do desenvolvimento profissional do magistério ${ }^{(12)}$. A formação continuada assim estaria baseada na valorização e no resgate do saber docente construído na prática pedagógica, em um processo mediado por referências teóricas e práticas.

Autores como Alarcão (1998), Nascimento (2000), Santos (1998), Schön (1992), Sacristán (1991), Nóvoa (1991) defendem a incorporação da prática interativoreflexiva (ligada à resolução de problemas reais) nos programas de capacitação de professores. Essa seria a prática capaz de melhor preparar o docente para o enfrentamento de situações futuras, uma vez que o torna mais consciente de seus padrões de trabalho, dos princípios, pressupostos e valores subjacentes a suas rotinas e seus hábitos de trabalho.

Do ponto de vista operacional, a melhor proposta de formação seria aquela que ajustasse o grupo a ser capacitado, os problemas identificados para serem trabalhados, os recursos humanos e materiais disponíveis (SANTOS, 1998), integrando as três dimensões da estrutura organizacional: o nível decisório, o processo, os fatores facilitadores da participação do pessoal envolvido (PEREIRA, 1995).

O desafio que a capacitação de professores coloca é o de saber compatibilizar as necessidades e as especificidades ou perfis dos professores com a demanda pela qualificação em massa, uma vez que as extensas redes públicas de ensino possuem professores com formação e tempo de trabalho (novatos, antigos etc.) diferenciados, com dupla jornada de trabalho, bem como escolas com necessidades, clientelas e gestões diferenciadas. A minimização desses obstáculos pode fazer a diferença no sentido de o professor ter uma qualificação mais eficaz e mais próxima da sua realidade. 


\section{Os Professores e a Diversidade na Escola}

Para explorar a relação docente e desempenho dos alunos foram construídos índices com os dados da pesquisa realizada em doze escolas localizadas nos municípios mineiros de Montes Claros e Januária que permitiram relacionar o perfil do professor com a situação das escolas pesquisadas, atenção pedagógica dispensada aos alunos e tipo de gestão escolar ${ }^{(13)}$.

O Índice do Perfil do Professor (IPP) foi construído a partir de dados sobre a escolaridade e a experiência de docência do professor (Tabela 2). Os indicadores utilizados para a elaboração do IPP foram: o nível de escolaridade do professor, o seu tempo de atuação na escola pesquisada (em número de anos), o tempo em que leciona na quarta série (série dos alunos pesquisados), o número de horas diárias de trabalho remunerado.

Tabela 2: Índice do Perfil dos Professores das Escolas - IPP*

\begin{tabular}{c|c|c|c|c}
\hline NOME & REDE & MUNICÍPIO & ÍNDICES & CLASSIFICAÇ्̃ O \\
\hline $\mathrm{A}^{(14)}$ & Municipal & Montes Claros & 6,0 & $\mathrm{M}$ \\
$\mathrm{B}$ & Municipal & Montes Claros & 6,0 & $\mathrm{M}$ \\
$\mathrm{C}$ & Municipal & Montes Claros & 5,0 & $\mathrm{R}$ \\
$\mathrm{D}$ & Estadual & Montes Claros & 8,0 & $\mathrm{~B}$ \\
$\mathrm{E}$ & Estadual & Montes Claros & 7,0 & $\mathrm{M}$ \\
$\mathrm{F}$ & Estadual & Montes Claros & 4,0 & $\mathrm{R}$ \\
$\mathrm{G}$ & Municipal & Januária & 5,0 & $\mathrm{R}$ \\
$\mathrm{H}$ & Municipal & Januária & 4,0 & $\mathrm{R}$ \\
$\mathrm{I}$ & Municipal & Januária & 5,0 & $\mathrm{R}$ \\
$\mathrm{J}$ & Estadual & Januária & 3,0 & $\mathrm{R}$ \\
$\mathrm{K}$ & Estadual & Januária & 10,0 & $\mathrm{~B}$ \\
$\mathrm{~L}$ & Estadual & Januária & 7,0 & $\mathrm{M}$ \\
\hline
\end{tabular}

Fonte: Dados da pesquisa Descentralização, eficiência e equidade no ensino fundamental, Escola de Governo/Fundação João Pinheiro; FAPEMIG, 1999.

*O índice é a soma dos valores codificados para cada uma dos indicadores utilizados, podendo assumir os valores de 0 a 15 .

Obs. Para o índice do perfil dos professores das escolas (IPP), as três faixas de referências ficaram da seguinte forma:

faixa 1: $x \leq 5,0$, indicando situação ruim em relação ao perfil dos professores;

faixa 2: 5,0 $<x \leq 7,0$, indicando situação média em relação ao perfil dos professores;

faixa 3: $x>7,0$, indicando situação boa em relação ao perfil dos professores;

Obs. $x$ é o índice do perfil dos professores para uma determinada escola.

O IPP permitiu verificar que a escola K (Januária) é a que apresenta situação mais favorável dentre as escolas analisadas, tendo obtido 10 pontos, numa escala de 0 a 13, seguida da escola D (Montes Claros) com 8 pontos. A escola mais mal classificada, com 3 pontos, é a escola J (Januária). Nenhuma das escolas da amostra atingiu a pontuação máxima. Percebe-se que as escolas pesquisadas apresentam, em sua maioria, condições pouco satisfatórias no que se refere ao 
perfil dos docentes, pois apenas duas foram consideradas boas em um total de 12 escolas, ambas da rede estadual. Contudo a situação do município de Montes Claros é um pouco melhor quanto a este item: das seis escolas pesquisadas, quatro situam-se nas posições média e boa, enquanto em Januária quatro receberam pontuação ruim. Ressalta-se que a rede estadual teve mais escolas classificadas como boas e médias do que a rede municipal quanto ao perfil do professor.

\section{O Índice da Atenção Pedagógica dispensada pelos professores - (IAPP)} reflete a atenção pedagógica dispensada aos alunos pelas escolas, sob a ótica dos professores pesquisados (Tabela 3).

Os dados utilizados na construção do IAPP se referem à existência ou não de programas desenvolvidos na escola com a finalidade de oferecer algum tipo de auxílio àquelas crianças que necessitam de maior acompanhamento nas atividades escolares, por estarem apresentando desempenho fraco, ou seja, acompanhamento especial para crianças com desempenho fraco, aulas extras (antes e depois do horário escolar) para as crianças com dificuldade de aprendizagem. O índice também utiliza informações sobre treinamento e capacitação dos professores e a freqüência com que esses programas de capacitação foram oferecidos.

Tabela 3: Índice da Atenção Pedagógica Dispensada pelos Professores - IAPP*

\begin{tabular}{c|c|c|c|c}
\hline NOME & REDE & MUNICÍPIO & ÍNDICES & CLASSIFICAÇ्̃ O \\
\hline A & Municipal & Montes Claros & 10,0 & $\mathrm{~B}$ \\
B & Municipal & Montes Claros & 9,0 & $\mathrm{~B}$ \\
C & Municipal & Montes Claros & 3,0 & $\mathrm{R}$ \\
D & Estadual & Montes Claros & 4,0 & $\mathrm{M}$ \\
E & Estadual & Montes Claros & 12,0 & $\mathrm{~B}$ \\
F & Estadual & Montes Claros & 3,0 & $\mathrm{R}$ \\
G & Municipal & Januária & 9,0 & $\mathrm{~B}$ \\
H & Municipal & Januária & 4,0 & $\mathrm{M}$ \\
I & Municipal & Januária & 2,0 & $\mathrm{R}$ \\
J & Estadual & Januária & 5,0 & $\mathrm{M}$ \\
K & Estadual & Januária & 3,0 & $\mathrm{R}$ \\
L & Estadual & Januária & 4,0 & $\mathrm{M}$ \\
\hline
\end{tabular}

Fonte: Dados da pesquisa Descentralização, eficiência e eqüidade no ensino fundamental, Escola de Governo/Fundação João Pinheiro; FAPEMIG, 1999.

*O índice é a soma dos valores codificados para cada uma dos indicadores utilizados, podendo assumir os valores de 0 a 12 .

Obs. Para o índice da atenção pedagógica para crianças com desempenho fraco (IAPP), as três faixas de referências ficaram da seguinte forma:

faixa 1: $x \leq 3,6$, indicando situação ruim em relação à atenção pedagógica;

faixa 2: 3,6 < x $\leq 6,0$, indicando situação média em relação à atenção pedagógica;

faixa 3: $x>6,0$, indicando situação boa em relação à atenção pedagógica.

Obs. x é o índice da atenção pedagógica para crianças com desempenho fraco para uma determinada escola. 
De acordo com o Índice da Atenção Pedagógica - (IAPP), a escola mais comprometida com este aspecto foi a escola E da rede estadual (Montes Claros), única de toda a amostra que obteve a pontuação máxima numa escala entre $0 \mathrm{e}$ 12, seguida da escola A (Montes Claros- municipal), com 10 pontos. A escola I (Januária - municipal) foi a mais mal classificada, com 2 pontos. No geral, do ponto de vista da atenção pedagógica, as redes estadual e municipal apresentaram desempenho similar.

O Índice do Apoio ao Desenvolvimento da Aprendizagem (IADA) foi elaborado com base nas informações sobre o tempo dispensado pelos professores, em sala de aula, para atividades relacionadas a exercícios práticos e utilização de manuais das disciplinas: foram levantados, neste caso, os dados referentes às disciplinas Português e Matemática. Os indicadores utilizados na construção do IADA foram: o número de horas semanais usadas para a leitura em sala de aula; a proporção de alunos da classe que possuem o livro-texto; a freqüência com que os livros-texto são utilizados; o número de horas semanais usadas para a leitura de livros não didáticos durante o período escolar; o número de horas semanais usadas para exercícios práticos de Matemática e o número de horas utilizadas, em sala de aula, para a correção dos exercícios dos alunos.

\section{Tabela 4: Índice do Apoio ao Desenvolvimento da Aprendizagem - IADA*}

\begin{tabular}{c|c|c|c|c}
\hline NOME & REDE & MUNICÍPIO & ÍNDICES & CLASSIFICAÇ̃̃O \\
\hline A & Municipal & Montes Claros & 8,0 & $\mathrm{M}$ \\
B & Municipal & Montes Claros & 9,0 & $\mathrm{M}$ \\
C & Municipal & Montes Claros & 10,0 & $\mathrm{~B}$ \\
D & Estadual & Montes Claros & 10,0 & $\mathrm{~B}$ \\
E & Estadual & Montes Claros & 9,0 & $\mathrm{M}$ \\
F & Estadual & Montes Claros & 9,0 & $\mathrm{M}$ \\
G & Municipal & Januária & 12,0 & $\mathrm{~B}$ \\
H & Municipal & Januária & 6,0 & $\mathrm{R}$ \\
I & Municipal & Januária & 6,0 & $\mathrm{R}$ \\
J & Estadual & Januária & 9,0 & $\mathrm{~B}$ \\
K & Estadual & Januária & 6,0 & $\mathrm{R}$ \\
L & Estadual & Januária & 7,0 & $\mathrm{R}$ \\
\hline
\end{tabular}

Fonte: Dados da pesquisa Descentralização, eficiência e eqüidade no ensino fundamental, Escola de Governo//Fundação João Pinheiro; FAPEMIG, 1999.

*O índice é a soma dos valores codificados para cada uma dos indicadores utilizados, podendo assumir os valores de 0 a 16 .

Obs. Para o índice do desenvolvimento de aprendizagem (IADA), as três faixas de referências ficaram da seguinte forma:

faixa 1: $x \leq 7,6$, indicando situação ruim em relação ao apoio ao desenvolvimento da aprendizagem; faixa 2: 7,6 $<\mathrm{x} \leq 9,0$, indicando situação média em relação ao apoio do desenvolvimento da aprendizagem;

faixa 3: $x>9$ 9,0, indicando situação boa em relação ao apoio do desenvolvimento da aprendizagem. Obs. x é o índice do apoio ao desenvolvimento de aprendizagem para uma determinada escola. 
De acordo com o IADA (Tabela 4), a escola G (Januária) foi a que dedicou maior parte do tempo das aulas às atividades voltadas para o desenvolvimento da aprendizagem dos alunos, tendo obtido 12 pontos, numa escala de 0 a 16 , seguida pelas escolas $\mathrm{C}$ e $\mathrm{D}$, ambas com 10 pontos e situadas no município de Montes Claros. As mais mal classificadas, com 6 pontos, foram as escolas H, I e K, localizadas em Januária.

O índice revela uma situação relativamente satisfatória com relação ao tempo destinado pelos professores das escolas pesquisadas ao apoio do desenvolvimento da aprendizagem em sala de aula, uma vez que, embora nenhuma delas tenha obtido os 16 pontos máximos, o intervalo entre a pontuação da melhor e das piores escolas classificadas é de 4 pontos.

$O$ índice da gestão centrada em dimensões pedagógicas (IGDP) foi construído a partir de dados sobre a percepção do professor em relação aos aspectos da organização escolar considerada como suporte para que o seu trabalho se desenvolva de maneira adequada, a fim de garantir o bom desempenho do aluno. Para tanto, foram utilizados os seguintes indicadores: porcentagem de professores da escola que têm procurado mudar sua prática de ensino, ajustandoa ao novo modelo educacional (baseado na pluralidade pedagógica); o nível do suporte dado pela biblioteca da escola ao trabalho do professor; a existência ou não de uma avaliação do trabalho docente pela direção da escola e pela Secretaria de Educação (estadual ou municipal, dependendo da rede de ensino à qual a escola é vinculada); planejamento das aulas elaborado de forma integrada com o trabalho de outros professores que atuam na mesma turma.

O IGDP (Tabela 5) indica que as escolas G e K (ambas municipais e situadas em Januária) foram as mais bem classificadas quanto a este aspecto, obtendo 6 pontos, numa escala de 0 a 6 . O IGDP revela uma situação bastante satisfatória das escolas da amostra com relação ao suporte pedagógico oferecido para o desenvolvimento das atividades dos professores. Como já foi mencionado, a escala de pontuação deste índice varia de 0 a 6 pontos e verifica-se que as escolas mais mal classificadas obtiveram 4 pontos sendo, portanto, muito pequeno o intervalo entre a pontuação das melhores e das piores classificadas, o que demonstra que, sob este aspecto, as duas redes se equiparam. 
Tabela 5: Índice da Gestão Centrada a Dimensões Pedagógicas - IGDP*

\begin{tabular}{c|c|c|c|c}
\hline NOME & REDE & MUNICÍPIO & ÍNDICES & CLASSIFICAÇÃO \\
\hline A & Municipal & Montes Claros & 5,0 & $\mathrm{M}$ \\
B & Municipal & Montes Claros & 5,0 & $\mathrm{M}$ \\
C & Municipal & Montes Claros & 4,0 & $\mathrm{R}$ \\
D & Estadual & Montes Claros & 4,0 & $\mathrm{R}$ \\
E & Estadual & Montes Claros & 5,0 & $\mathrm{M}$ \\
F & Estadual & Montes Claros & 5,0 & $\mathrm{M}$ \\
G & Municipal & Januária & 6,0 & $\mathrm{~B}$ \\
H & Municipal & Januária & 4,0 & $\mathrm{R}$ \\
I & Municipal & Januária & 4,0 & $\mathrm{R}$ \\
J & Estadual & Januária & 4,0 & $\mathrm{R}$ \\
K & Estadual & Januária & 6,0 & $\mathrm{~B}$ \\
L & Estadual & Januária & 5,0 & $\mathrm{M}$ \\
\hline
\end{tabular}

Fonte: Dados da pesquisa. Descentralização, eficiência e eqüidade no ensino fundamental, Escola de Governo/Fundação João Pinheiro; FAPEMIG, 1999.

*O índice é a soma dos valores codificados para cada uma dos indicadores utilizados, podendo assumir os valores de 0 a 6.

Obs. Para o índice da gestão centrada a dimensões pedagógicas (IGDP), as três faixas de referências ficaram da seguinte forma:

faixa 1: $x \leq 4,0$, indicando situação ruim na gestão centrada em dimensões pedagógicas;

faixa 2: $4,0<\mathrm{x} \leq 5,0$, indicando situação média na gestão centrada em dimensões pedagógicas; faixa 3: $x>5,0$, indicando situação boa na gestão centrada em dimensões pedagógicas.

Obs. x é o índice da gestão centrada a dimensões pedagógicas para uma determinada escola.

\section{Situação Socioeconômica das Crianças e a Atenção Pedagógica Recebida}

A pesquisa envolveu, além de informações sobre práticas pedagógicas e modelos de gestão, coleta de dados junto às famílias dos alunos que compunham as turmas selecionadas e aplicação de testes padronizados em português e matemática às crianças dessas turmas. A partir da apuração dos dados do questionário socioeconômico, foi possível caracterizar a clientela das escolas. $\mathrm{O}$ indicador utilizado aqui para situar as características socioeconômicas dos alunos é a porcentagem de crianças de status socioeconômico (SSE) baixo, médio e bom, em cada turma pesquisada nas escolas escolhidas para amostra. Como pode ser observado no Quadro 1, as escolas pesquisadas atendem clientelas bem diferenciadas, sendo que as escolas de Januária concentram crianças provenientes de ambientes familiares menos propícios à aprendizagem e, portanto, mais dependentes da instituição escolar para enfrentar os desafios da escolarização. 


\section{Quadro 1: Síntese dos Resultados dos Índices Aplicados e Desempenho Escolar}

\begin{tabular}{|c|c|c|c|c|c|c|c|c|c|c|c|}
\hline \multirow{2}{*}{$\begin{array}{c}\text { Escola } \\
\text { A }\end{array}$} & \multirow{2}{*}{$\begin{array}{c}\begin{array}{c}\text { Clientela } \\
\text { \% de crianças } \\
\text { SSE baixo* }\end{array} \\
42,1\end{array}$} & \multicolumn{2}{|c|}{$\begin{array}{c}\text { IPP/ } \\
\text { Classificação } \\
\text { (Variação: 0-15) }\end{array}$} & \multicolumn{2}{|c|}{$\begin{array}{c}\text { IAP/ } \\
\text { Classificação } \\
\text { (Variação: 0-12) }\end{array}$} & \multicolumn{2}{|c|}{$\begin{array}{c}\text { IADA/ } \\
\text { Classificação } \\
\text { (Variação: 0-16) }\end{array}$} & \multicolumn{2}{|c|}{$\begin{array}{c}\text { IGCP/ } \\
\text { Classificação } \\
\text { (Variação: 0-6) }\end{array}$} & \multirow{2}{*}{\begin{tabular}{c|}
$\begin{array}{c}\text { Nota Média } \\
\text { Português } \\
(* *)\end{array}$ \\
13,9 \\
\end{tabular}} & \multirow{2}{*}{$\begin{array}{c}\begin{array}{c}\text { Nota Média } \\
\text { Matemática }\end{array} \\
14,1 \\
\end{array}$} \\
\hline & & 6 & $\mathrm{M}$ & 10 & $\mathrm{~B}$ & 8 & $\mathrm{M}$ & 5 & $M$ & & \\
\hline B & 20,0 & 6 & $M$ & 9 & B & 9 & $\mathrm{M}$ & 5 & $\mathrm{M}$ & 24,3 & 19,9 \\
\hline $\mathrm{C}$ & 39,1 & 5 & $\mathrm{R}$ & 3 & $\mathrm{R}$ & 10 & B & 4 & $\mathrm{R}$ & 21,1 & 17,8 \\
\hline $\mathrm{D}$ & 23,8 & 8 & B & 4 & $\mathrm{M}$ & 10 & $\mathrm{~B}$ & 4 & $\mathrm{R}$ & 20,3 & 17,7 \\
\hline $\mathrm{E}$ & 4,2 & 7 & $M$ & 12 & $\mathrm{~B}$ & 9 & $\mathrm{M}$ & 5 & $\mathrm{M}$ & 30,1 & 21,5 \\
\hline $\mathrm{F}$ & 0,0 & 4 & $\mathrm{R}$ & 3 & $\mathrm{R}$ & 9 & $\mathrm{M}$ & 5 & $\mathrm{M}$ & 30,0 & 23,0 \\
\hline $\mathrm{G}$ & 87,5 & 5 & $\mathrm{R}$ & 9 & B & 12 & B & 6 & B & 11,1 & 11,1 \\
\hline $\mathrm{H}$ & 83,3 & 4 & $\mathrm{R}$ & 4 & $\mathrm{M}$ & 6 & $\mathrm{R}$ & 4 & $\mathrm{R}$ & 17,6 & 12,8 \\
\hline I & 80,0 & 5 & $\mathrm{R}$ & 2 & $\mathrm{R}$ & 6 & $\mathrm{R}$ & 4 & $\mathrm{R}$ & 18,7 & 15,0 \\
\hline $\mathrm{J}$ & 12,5 & 3 & $\mathrm{R}$ & 5 & $\mathrm{M}$ & 9 & $\mathrm{M}$ & 4 & $\mathrm{R}$ & 24,6 & 20,6 \\
\hline $\mathrm{K}$ & 43,5 & 10 & B & 3 & $\mathrm{R}$ & 6 & $\mathrm{R}$ & 6 & $\mathrm{~B}$ & 13,1 & 14,3 \\
\hline $\mathrm{L}$ & 50,0 & 7 & $M$ & 4 & $\mathrm{M}$ & 7 & $\mathrm{R}$ & 5 & $\mathrm{M}$ & 15,7 & 13,4 \\
\hline
\end{tabular}

Fonte: Dados da pesquisa Descentralização, eficiência e equidade no ensino fundamental, Escola de Governo/FJP; FAPEMIG, 1999.

* SSE - Status socioeconômico da clientela em estudo

** Nota máxima Português = 32; nota máxima Matemática $=46$

IPP - Índice do Perfil do Professor

IAP - Índice de Atenção Pedagógica

IADA - Índice de apoio ao Desenvolvimento da Aprendizagem

IGCP - Índice de Gestão Centrada em Aspectos Pedagógicos

Classificação das escolas com relação à variável analisada

B BOA situação

M Situação MÉDIA

R Situação RUIM

No entanto o que se observa é que os professores que alcançaram melhores pontuações no índice Perfil do Professor (IPP) tendem a se localizar em escolas que atendem crianças em situação socioeconômica um pouco mais favorável (escolas do município de Montes Claros, excetuando-se a escola F) e que as escolas que concentram a clientela com a maior proporção de SSE n(G, H e I) contam com professores que apresentam perfil classificado como ruim, segundo o IPP. Contudo o perfil adequado, de acordo com IPP não se reflete, necessariamente, em práticas e gestão centradas nas dimensões pedagógicas: a escola D de Montes Claros, por exemplo, é classificada como boa em perfil do professor, como média em atenção pedagógica, como boa em apoio ao desenvolvimento da aprendizagem e como ruim em gestão centrada em dimensões pedagógicas. A escola G, localizada no município de Januária, por sua vez, atende uma clientela majoritária de crianças de SSE baixo (87,5\%); é classificada como tendo professores de perfil ruim (menos experientes); mas se destaca nas dimensões relacionadas ao desenvolvimento de atividades de apoio às crianças com dificuldades de aprendizagem e de exploração de técnicas de ensino diversificadas. A escola K, também em Januária, tem uma clientela mista, alcança a pontuação mais alta no índice do perfil do professor; mas tem pontuação mais 
baixa em atenção pedagógica e de apoio ao desenvolvimento da aprendizagem. Algo semelhante ocorre com a escola L de Januária.

Embora as condições intra-escolares favoráveis oferecidas pela escola $G$ não se manifestem ainda no rendimento escolar de seus alunos (11,1 pontos em Português e Matemática) ${ }^{(15)}$, ela é uma escola que está atuando na direção apropriada para incluir uma clientela em condições desfavoráveis.

Comparativamente, a escola K (Januária) que atende a uma clientela mista (43,5\% SSE baixo), possui a melhor classificação com relação aos índices perfil do professor e gestão, também apresenta rendimento fraco nos testes aplicados (13,1 pontos em Português e 14,3 em Matemática); o que mostra que para se obter um bom rendimento é necessário que ocorram ações conjuntas (intra e extra escolares) integradas. O investimento em uma única dimensão parece insuficiente para corrigir processos amplos de exclusão.

Embora a escola $\mathrm{G}$ não tenha ainda conseguido resultados favoráveis em relação ao rendimento de seus alunos, ela pode ser considerada, entre as unidades escolares pesquisadas, a que melhor desempenha o papel que se espera de uma instituição pública de ensino fundamental a partir do novo modelo educacional brasileiro, em face do apoio pedagógico que oferece e do tipo de gestão que adota. Essa escola consegue, com sua clientela composta por crianças oriundas de contextos mais adversos, um desempenho próximo àquele de escolas em melhores condições.

O resultado da escola $G$ desperta o interesse em conhecer o que acontece nessa escola. A visita às escolas permitiu verificar, que além de uma gestão mais aberta e democrática, existe por parte da direção o esforço de interação da escola com a comunidade, facilitando o acesso das famílias em horários fora do período de aulas, mesmo nos fins de semana: jogos de futebol entre pais e alunos, aulas de artesanato para os alunos, empréstimo de espaços da área de lazer para comemorações da comunidade. Tal atitude favorece uma cumplicidade entre a população e a escola de forma que aquelas famílias menos sensíveis à vida escolar dos filhos passam a se interessar mais pelo desempenho das crianças, a conhecer melhor o diretor, os professores e orientadores, enfim todo o universo relacionado às atividades diárias da criança. Tal situação tende a fortalecer o papel da escola junto à comunidade, o que pode influenciar positivamente os resultados do rendimento escolar dos alunos.

O planejamento pedagógico da escola, considerado importante fator na construção de um novo modelo escolar, deve levar em consideração os interesses e necessidades da comunidade e ser elaborado com base na realidade local e 
com a participação das famílias que compõem a sua clientela. No entanto resultados de avaliações realizadas por estudiosos da área mostram que esse instrumento de planejamento ainda é incipiente e que as escolas mais carentes não dispõem de pessoal técnico para sistematizar as propostas e transformá-las em plano coerente de ação. Mais uma vez destaca-se o diferencial da escola G que, apesar das dificuldades enfrentadas consegue bom desempenho com relação aos índices de atenção pedagógica e de apoio ao desenvolvimento da aprendizagem. Tal experiência mereceria ser divulgada como estudo de casos nos próprios programas de capacitação e também servir de modelo para outras unidades escolares que tenham clientela e estejam localizadas em comunidades com características semelhantes àquelas da escola em estudo.

Constata-se, pelos dados aqui trabalhados, que as escolas estaduais são as que concentram o maior número de crianças de situação socioeconômica mais favorável e que apresentam melhor rendimento. Já as escolas municipais absorvem crianças de situação socioeconômica baixa e são as que apresentam o pior rendimento dos alunos nos testes aplicados.

Outra constatação é que nem sempre as crianças de situação desfavorável estão nas melhores escolas quanto aos aspectos pedagógicos, o que sinaliza que as escolas públicas de ensino fundamental ainda estão muito aquém do que delas se esperaria para lidar com a diversidade socioeconômica e cultural das crianças; o desejável seria que as escolas oferecessem persistentes ações para contrabalançar os efeitos negativos de inserção sociocultural desfavorável. Assim, mesmo que não se possa afirmar que o círculo perverso da desigualdade e da exclusão esteja se reproduzindo, de forma sistemática, também não se pode afirmar que ele esteja sendo rompido por práticas intra-escolares e atenção do poder público claramente definidos para esse fim.

Os dados mostraram ainda uma forte associação entre SSE das crianças e rendimento escolar: em geral, as médias foram mais altas nas escolas com menor porcentagem de crianças de SSE baixo; isso fica claro na escola F. Esse resultado corrobora algo destacado na literatura especializada: é necessário que as instituições escolares que recebem crianças com perfil SSE menos propício à escolarização, tenham professores mais qualificados, desenvolvendo regularmente atividades centradas no apoio pedagógico, de forma a suprir os efeitos da condição socioeconômica desfavorável do ambiente familiar do aluno.

Tais informações tornam-se relevantes no planejamento da capacitação do corpo docente, onde estão os professores mais bem e mais mal qualificados. Que clientela eles atendem? Onde estão os alunos com melhor e pior rendimento? Esses questionamentos permitem mapear as reais necessidades da capacitação: 
que aspectos devem ser priorizados, que tipo de capacitação oferecer e que regiões devem ser atendidas mais rapidamente.

Têm-se então indicações de temas a serem explorados em cursos de capacitação e em ações das secretarias de educação. Uma capacitação adequada seria aquela que, além do reforço da formação acadêmica, considerasse a integração de ações como a atenção pedagógica, o modelo de gestão escolar, o despertar de habilidades nos professores, para que possam driblar as adversidades do contexto escolar e a divulgação de experiências bem sucedidas.

Nesse contexto, a capacitação de professores ganha destaque como uma das medidas a ser adotada para que eles possam enfrentar o desafio de tornar a escola uma agência pública mais includente. Portanto ampliar a cobertura escolar é insuficiente, pois não basta colocar as crianças dentro das escolas; as unidades de ensino devem ser capazes de realizar sua missão organizacional, ou seja, ensinar àqueles que lá se encontram para aprender.

\section{Considerações Finais}

Dadas as mudanças introduzidas no contexto educacional brasileiro, principalmente com a ampliação do acesso e conseqüente aumento da diversidade do alunado, a figura do professor ganha maior importância no que diz respeito ao desempenho escolar. Observa-se que professores menos preparados se encontram nas escolas cuja clientela demanda um profissional mais bem qualificado e mais inovador, o que reforça uma distribuição desigual e injusta.

Porém a capacitação dos docentes, nos moldes como se tem apresentado, também não tem sido eficaz no sentido de prepará-los adequadamente para enfrentar os desafios instituídos pelo novo modelo de ensino que passa a aceitar a pluralidade pedagógica, visando ao melhor desempenho dos alunos.

Nesse sentido, a prática da reflexão crítica torna-se um fator facilitador do controle do processo de mudança pelo qual a escola passa, tornando-a mais bem qualificada para adaptar as medidas apresentadas pelas políticas atuais. Isso demanda uma formação que instrumentalize os docentes para o exercício constante da reflexão, o trabalho cooperativo e coordenado de modo que possam beneficiar-se das experiências bem sucedidas, e para a atenção constante às necessidades e particularidades de seus alunos. A escola, por sua vez, deve criar espaços para a reflexão, para o exercício da criatividade e da cooperação. 
Os problemas apontados reforçam a necessidade de se observar um determinado conjunto de fatores para uma capacitação ser bem-sucedida: que ela seja demandada pelos professores; que os professores priorizem os conteúdos dos treinamentos; que a capacitação resulte de um trabalho integrado entre professores, diretores, secretarias municipais de educação, secretarias estaduais da educação e capacitadores; que se respeitem as relações históricas entre as instituições envolvidas e que se leve em consideração a heterogeneidade dos profissionais do ensino: formação, tempo de trabalho e tipos de dificuldades que enfrentam.

O que se pretende destacar não é a simples inserção do professor no processo de capacitação, mas a inserção e a interação de diferentes atores nesse processo: professores, diretores, autoridades educacionais, universidades e outros. $\mathrm{O}$ destaque dado ao professor no decorrer desse texto não significa ignorar a dimensão política desse processo, mas atentar para a redefinição dos papéis dos envolvidos na capacitação.

O exame de programas de capacitação sugere que sejam considerados os tipos de municípios, os tipos de clientela da escola, a formação e o tempo de trabalho dos professores, possibilitando desenhos flexíveis de capacitação. Talvez fosse importante introduzir em tais programas um módulo para a formação do professor, de forma que os docentes se sentissem mais preparados para lidar com as novas tarefas emergentes da proposta pedagógica atual. É importante também que a capacitação ocorra na unidade escolar e seja voltada para a escola como um todo, mas sem prescindir da colaboração dos outros atores. Segundo Santos (2000, p. 179) “(...) a literatura sobre formação continuada tem enfatizado a necessidade de se trabalhar o conjunto dos professores das escolas, com vistas a uma modificação coletiva das práticas nelas instaladas, uma vez que o trabalho, envolvendo apenas parte do corpo docente, pode ser dificultado, tanto pela não modificação na dinâmica de trabalhos na instituição, como pela ação de docentes não-sensibilizados para mudanças”.

Uma possibilidade seria a de que cada escola ou um conjunto de escolas pudessem realizar uma capacitação por ano com o apoio e coordenação das secretarias de educação. A escola, por meio da sua equipe, elegeria os principais temas a serem abordados e escolheria o seu melhor momento (data, horário), de maneira que os programas de capacitação implementados pudessem ser mais condizentes com a sua realidade, expectativa e necessidade do corpo docente. A obrigatoriedade de uma capacitação anual evitaria a descontinuidade do processo e manteria o professor entusiasmado com as novidades trazidas pela capacitação, estimulando-o a promover mudanças menos transitórias na sua prática. 
Capacitar professores, dentro desta proposta, não se limitaria apenas à exigências de titulação e formação acadêmica; seria necessário que as unidades escolares, ao elaborarem seus projetos pedagógicos, enfatizassem a atuação destes professores, estimulando a sua criatividade, fornecendo suporte para o desenvolvimento do seu trabalho, criando oportunidades para a troca de experiências entre os docentes por meio da oferta de treinamentos constantes e direcionados para a sua clientela e para a comunidade em que a escola se insere.

Contudo cabe citar Ibarrola (1998, p. 84) para quem a mudança na formação continuada do magistério não requer apenas novos programas, novos conteúdos, lógicas diferentes de articulação do conhecimento, mas reorganização do trabalho na escola, reorganização dos programas de formação e generoso financiamento.

Atrelar o desempenho do aluno à capacidade do professor e ao modelo de gestão adotado pela escola seria uma forma de diminuir o hiato existente entre 0 ambiente familiar desfavorável à sua educação e o seu aprendizado. Entretanto três pontos fundamentais devem ser considerados, a partir dos dados trabalhados nesse artigo: primeiro verifica-se que as variáveis mais fortemente ligadas ao desempenho escolar são as condições socioeconômicas e culturais das famílias das crianças e o perfil do professor que as atende; segundo, que as escolas que incorporam maior diversidade socioeconômica e cultural do alunado contam com professores com perfil menos adequado para lidar com essa clientela; e terceiro, que nem sempre as escolas que contam com os professores mais capacitados apresentam desenvolvimento de atividades centradas na atenção pedagógica.

Fica claro que a capacitação por si só não se reverte em melhoria do rendimento escolar. Há que se considerar um conjunto de fatores que deverão estar integrados como atenção pedagógica, gestão escolar flexível e aberta, ações que envolvam a participação da comunidade e melhoria nas condições de trabalho do professor: salários, equipamentos e outros. O modelo educacional vigente, mais flexível e includente, passa a exigir maior habilidade e competência dos profissionais do ensino que deverão, além dos procedimentos pedagógicos propostos pela escola, usar a sua criatividade na busca de novos métodos e técnicas que estimulem os alunos a desenvolver as atividades escolares com maior empenho e interesse, o que certamente deverá resultar em rendimento mais satisfatório das crianças.

Esclarece-se também a importância da gestão no planejamento de uma capacitação mais eficaz. No âmbito da escola ressalta-se a necessidade de uma gestão aberta, flexível, que crie condições para que o professor se capacite e abra espaços para que ele desenvolva sua autonomia na busca de inovação e interação de forma própria com seus alunos e seus colegas. No âmbito das secretarias de educação seria importante uma gestão preocupada em realizar 
atividades de diagnóstico que permitam mapear as reais necessidades de capacitação: onde estão os professores mais e menos qualificados, quais experiências inovadoras já aconteceram nos diferentes municípios, que aspectos deveriam ser realçados em cada capacitação: conteúdos, estímulo à criatividade, aspectos relativos às alterações pedagógicas propostas pela legislação vigente e outros.

\section{Artigo recebido em 07.11.2003. Aprovado em 02.07.2004.}

\section{Notas}

${ }^{1}$ A base empírica do trabalho é a pesquisa Descentralização, eficiência e equidade no ensino fundamental, desenvolvida pela Escola de Governo da Fundação João Pinheiro, de Belo Horizonte (MG) e financiada pela Fundação de Amparo à Pesquisa de Minas Gerais (FAPEMIG), realizada em cinco municípios mineiros: Belo Horizonte, Contagem, Montes Claros, Januária e Almenara; e as dissertações de mestrado intituladas "Os programas de capacitação de professores do ensino fundamental nos estados de Minas Gerais e São Paulo: uma análise comparativa” e "A interação entre as instituições públicas de ensino fundamental e a diversidade socioeconômica e cultural das crianças" apresentadas no Mestrado em Administração Pública da Escola de Governo da Fundação João Pinheiro.

${ }^{2}$ A capacitação nesses estados abrangeu todos os municípios e as redes estadual e municipal (Minas Gerais) e principalmente a estadual em São Paulo.

${ }^{3}$ De acordo com a contagem de 1996, realizada pelo IBGE, a escolarização de crianças na faixa etária de 7-14 anos é da ordem de 90\% em todo o país.

${ }^{4}$ A diversidade do alunado se traduz não apenas pela aceitação de crianças de raças, crenças, hábitos diferenciados ou provenientes de ambientes socioeconômicos e culturais desfavoráveis, mas também pela inclusão de alunos que apresentam dificuldade de aprendizagem em diferentes níveis.

${ }^{5}$ Ressalta-se que muitas escolas instituíram o sistema de promoção por avanços progressivos, ou progressão automática, que tinha por objetivos eliminar a repetência, diminuir os índices de evasão, a organizar os programas de ensino adaptados às peculiaridades regionais e ao aluno, e oferecer maior eficiência do ensino e maior aproveitamento das capacidades dos alunos. O suporte teórico baseia-se na psicologia diferencial e evolutiva que estuda o desenvolvimento da criança e as diferenças individuais. Ao considerar que o aluno se desenvolve num ritmo próprio, os sistemas de promoção por avanços progressivos possibilitariam a sua promoção, ao final do ano letivo, de acordo com a etapa de desenvolvimento em que se encontrava. Esse sistema valorizaria o progresso do aluno, estimulando-o a freqüentar a escola, em busca de novas aprendizagens e sucesso. Avançando por etapas sucessivas, o aluno não perderia tempo repetindo etapas já vencidas (CASTRO et al., 2000, p. 18-19).

${ }^{6}$ A proficiência de 150 pontos em Português significa que os alunos conseguem localizar informações explícitas em textos narrativos curtos. A mesma proficiência em Matemática indica, 
entre outras coisas, que o aluno fez as quatro operações básicas, lê horas e minutos em relógio digital e calcula o resultado de operações que envolvem intervalo de tempos.

${ }^{7}$ Foram aplicados questionários aos familiares das crianças da amostra e, a partir das informações obtidas, foram calculadas as faixas de referências, possibilitando classificar cada uma das famílias nos níveis baixo, médio e bom. Para o cálculo das faixas de referência foram definidos pontos de corte da distribuição amostral dos índices socioeconômicos, utilizando-se o percentil de 33\% de modo que cada faixa de referência contemplasse $1 / 3$ das famílias em estudo. A população pesquisada se situa numa faixa cuja renda familiar oscila entre $\mathrm{R} \$ 20,00$ e $\mathrm{R} \$ 5000,00$. De acordo com essa classificação serão consideradas: baixa renda (de $\mathrm{R} \$ 20,00$ até $\mathrm{R} \$ 250,00$ ); média (mais de $\mathrm{R} \$ 250,00$ até $\mathrm{R} \$ 500,00)$ e boa (mais de $\mathrm{R} \$ 500,00$ até $\mathrm{R} \$ 5.000,00$ ).

${ }^{8}$ A classificação dos professores como sendo bom, médio ou ruim obedeceu aos seguintes critérios: nível de escolaridade e experiência como docente. O professor considerado bom é aquele que possui nível universitário completo e/ou pós-graduação e acima de 10 anos de experiência; o professor considerado médio é aquele que possui ensino médio completo ou universitário incompleto e entre 5 e 9 anos de experiência; o professor considerado ruim é aquele que possui o ensino fundamental completo/incompleto ou o ensino médio incompleto e menos de cinco anos de experiência.

${ }^{9}$ Nascimento, 2000; Candau, 1997; Gatti et al., 1998; Santos, 1998; Perrenoud, 1999 e outros.

${ }^{10}$ De acordo com Forquin (1995, p. 46), a escolarização se reveste de uma significação completamente diferente em se tratando de uma criança de um meio social elevado ou não. Para o autor, a criança de meio social elevado possivelmente encontrará na linguagem utilizada na escola simplesmente o prolongamento e desenvolvimento de maneiras de ser inculcadas desde a primeira infância. Já a criança oriunda de determinadas frações da classe operária é confrontada com as exigências de uma acomodação verdadeiramente "desculturante" e que constitui uma ameaça para sua identidade. "É a própria escola, em grande parte, responsável pelo fracasso escolar das crianças de meios populares, porque veicula uma cultura e uma simbologia fundamentalmente estranhas à sua cultura, destruidoras de sua identidade, e que a desqualificam ao pretender 'salválas'” (FORQUIN, 1995, p. 47).

${ }^{11}$ Embora as análises sobre a capacitação oferecida aos professores em Minas Gerais e sobre as condições socioeconômica dos alunos e desempenho constem de diferentes trabalhos, a capacitação que subsidia a análise aqui realizada é a mesma. Foram aplicados questionários aos professores em que respondiam sobre capacitações de que tinham participado. Todos afirmaram ter participado do PROCAP (capacitação realizada a todos professores da rede pública do estado de Minas Gerais, no período 1996-1998. Os questionários foram aplicados no ano de 2000).

${ }^{12}$ Não se deve tratar do mesmo modo o professor em fase inicial do exercício profissional, aquele que já conquistou uma ampla experiência pedagógica e aquele que já está se situando em relação à aposentadoria, em razão de os problemas, necessidades e desafios serem diferentes. Dessa forma, os processos de formação continuada não podem ignorar essa realidade, promovendo situações homogêneas e padronizadas.

${ }^{13}$ Na pesquisa os professores das turmas selecionadas respondera a questionários com perguntas sobre a participação em cursos de capacitação, práticas docentes, qualificação e experiência docente. As famílias dos alunos responderam a questionários por meio dos quais se procurava identificar as condições socioeconômicas familiares. Foram aplicados testes de português e matemática nos alunos da 4 série do ensino fundamental (adaptação dos testes preparados pela UNESCO-URELAC). Foram ainda observadas as práticas docentes em sala de aula. Os índices 
somatórios simples utilizam os dados dos questionários dos docentes. O rendimento escolar foi determinado a partir dos resultados dos testes aplicados aos alunos.

${ }^{14}$ Com o objetivo de se preservar a identidade das escolas pesquisadas, serão aqui utilizadas letras para identificá-las.

${ }^{15}$ Para se verificar as médias do rendimento dos alunos por escola, foram aplicadas pelos pesquisadores provas de Português e Matemática. A nota máxima a ser obtida pelas crianças seria 32 pontos em Português e 46 em Matemática.

\section{REFERÊNCIAS Biblográficas}

\section{ALARCÃO, I.}

Formação continuada como instrumento de profissionalização docente. In: VEIGA, I. P.A. (Org.). Caminhos da Profissionalização do Magistério. São Paulo: Papirus Editora, 1998.

BONAMINO, A. M. C.

O Sistema Nacional de Avaliação da Educação Básica (SAEB): referências, agentes e arranjos institucionais e instrumentais. 2000. $120 \mathrm{f}$. Tese (Doutorado em Educação) - PUC/Rio, Rio de Janeiro.

\section{BRASIL.}

Ministério da Educação e Cultura. Lei n. 9.394 de 20 de dezembro de 1996 . Estabelece as diretrizes e bases da educação nacional. In: BRZEZINSKI, I. (Org.). LDB Interpretada: diversos olhares se entrecruzam. 3. ed. São Paulo: Cortez, 2000. p. 246-308.

\section{CANDAU, V. M. F.}

Formação continuada de professores: tendências atuais. In: CANDAU, V. M. (Org.). Magistério: construção cotidiana. Petrópolis: Vozes, 1997, p. 51-68.
CASTRO, J. A. de et al.

A reestruturação das políticas federais para o ensino fundamental: descentralização e novos mecanismos de gestão. Rio de Janeiro: IPEA. 2000. Texto para discussão, n. 745, p. 94.

DUARTE, V.C.

Os programas de capacitação de professores do ensino fundamental nos estados de Minas Gerais e São Paulo: uma análise comparativa. 2002, 217 f. Dissertação (Mestrado em Administração Pública) - Escola de Governo, Fundação João Pinheiro, Belo Horizonte.

FORQUIN, J. C. (Org.).

Sociologia da Educação: dez anos de pesquisa. Petrópolis: Vozes, 1995. p. 81144.

FUNDAÇÃO JOÃO PINHEIRO.

Escola de Governo. Contexto socioeconômico de desempenho educacional e descentralização financeira no ensino fundamental estadual de Minas Gerais. Belo Horizonte, 1999. Relatório de Pesquisa. 
GARRIDO, E.;

CARVALHO, A. M. P.

Reflexões sobre a prática e qualificação da formação inicial docente. Cadernos de Pesquisa. São Paulo: Fundação Carlos Chagas, n. 107, p. 149-168, jul. 1999.

GATTI, B. A. et al.

Características de professores(as) de $1^{\circ}$ grau: perfil e expectativas. In: SERBINO, R. V. et al. (Orgs.). Formação de professores. São Paulo: Fundação UNESP, 1998. p. 251-264.

GUSSO, D. A.

A educação básica. In: ALBUQUERQUE, R. C. (Coord.). O Brasil social: realidades, desafios, opções. Rio de Janeiro: IPEA, Série IPEA, n. 139, 1993. p. 153-187.

IBARROLA, M. de.

A recente experiência mexicana de formação básica e contínua de professores. In: SERBINO, R.V. et al. (Orgs.). Formação de professores. São Paulo: Fundação Editora da UNESP, 1998. p. 69-84.

INSTITUTO BRASILEIRO DE GEOGRAFIA E ESTATÍSTICA.

Contagem do Censo Demográfico: 1996, v. 2, Rio de Janeiro, 1997.

\section{MARIN, A. J.}

Educação continuada: introdução uma análise de termos e concepções. Cadernos CEDES, São Paulo, n. 36, p. 13-20, 1995.

\section{MEC/INEP.}

Censo escolar: Brasil, 2000. Brasília, DF, 2000. Disponível em: <http// www.inep.gov.br $>$. Acesso em: fev. 2003.

MELLO, G. N. de.

Políticas públicas de educação. São Paulo: Instituto de Estudos Avançados da Universidade de São Paulo. 1991. Série Educação para a Cidadania, n. 1, p. 66.

NASCIMENTO, M. G. das

A formação de professores e profissão docente: modelos, dimensões e problemática. Ciclo de Conferências da Constituinte Escolar. Caderno Temático, Belo Horizonte, n. 5, jun. 2000.

NÓVOA, A.

Concepção e práticas de formação contínua de professores. In: CONGRESSO NACIONAL DE FORMAÇÃO CONTÍNUA DE PROFESSOR. Formação contínua de professores: realidades e perspectivas. Portugal: Universidade de Aveiro, 1991. p. 7-23.

NUNES, L. C. P.

Ensino de primeiro grau e qualidade no Brasil hoje. In: ECONOMIA BRASILEIRAEM PERSPECTIVA, Rio de Janeiro: IPEA, v. 2. p. 475-493. 1996.

\section{PARAGUASSU, L.}

Atraso escolar atinge $41,7 \%$ dos alunos. Folha de S. Paulo, São Paulo, 28 jun. 2001. Cotidiano, p. C1. 
PEREIRA, R. da C.

Educação em serviço para o professor: dimensões de sua estrutura operacional. Revista Brasileira de Estudos Pedagógicos, Brasília: INEP, v. 75, n. 179/ 180/181, p. 33-63, jan./dez. 1995.

\section{PERRENOUD, $\mathrm{P}$.}

Construir as competências desde a Escola. Porto Alegre: Artes Médicas Sul, 1999. p. 90.

\section{SACRISTÁN, J. G.}

Consciência e ação sobre a prática como libertação profissional dos professores. In: NÓVOA, A. (Org.). Profissão professor. Portugal: Porto, 1991.

\section{SANTOS, L. L. C. P. de.}

Dimensões pedagógicas e políticas da formação contínua. In: VEIGA, I. P. A. (Org.). Caminhos da profissionalização do magistério. Campinas: Papirus, 1998. p. 123-136.

A implementação de políticas do Banco Mundial para a formação docente. Cadernos de Pesquisa, São Paulo, n. 111, p. 117-182, dez. 2000.
SCHÖN, D. A.

Formar professores como profissionais reflexivos. In: NÓVOA, A. (Org.). Os professores e a sua formação. Lisboa: Dom Quixote, 1992. p. 77-92.

VEIGA, L. da;

BARBOSA, M. L. O. de.

Os impactos e os limites das políticas educacionais. Teoria e Sociedade, Belo Horizonte, v. 2, p. 39-74, dez. 1997.

VEIGA, L. .

Programas para melhoria da aprendizagem no Brasil. In: LATIN AMERICAN STUDIES ASSOCIATION, 2001, Washington, DC: [Washington, DC: s.n., 2001]. 